\title{
Immunity and Vaccination against Tuberculosis in Cattle
}

\author{
Natalie A. Parlane $\cdot$ Bryce M. Buddle
}

Published online: 22 January 2015

(C) Springer International Publishing AG 2015

\begin{abstract}
Bovine tuberculosis (TB) continues to be a major animal health problem worldwide and new tools are required for the control of this disease in cattle, particularly with the emergence of wildlife reservoirs for Mycobacterium bovis infection and potential restrictions on trade. New insights into the roles of macrophages, dendritic cells, NK cells, and CD4+, $\mathrm{CD} 8+$, and $\gamma \delta$ T cells in control of $M$. bovis infection in cattle have provided a better understanding of protective immunity against this disease. In the past two decades, considerable progress has been made in the development and evaluation of TB vaccines for cattle, with new attenuated mycobacterial vaccines providing an alternative to the use of $B C G$ vaccine and sub-unit vaccines to boost protection induced by BCG. With the development of tests to differentiate infected from vaccinated animals, it is now feasible to use vaccines to assist in the control of this disease.
\end{abstract}

Keywords Bovine tuberculosis $\cdot$ Mycobacterium bovis . Immunity $\cdot$ Vaccination $\cdot$ Cattle

\section{Introduction}

Mycobacterium bovis, the causative agent of bovine tuberculosis (TB), is a member of the M. tuberculosis complex and infects a wide range of hosts including humans. The disease in cattle, defined as bovine TB, is a major economic animal

This article is part of the Topical Collection on Bacteriology

N. A. Parlane $\cdot$ B. M. Buddle $(\bowtie)$

AgResearch, Hopkirk Research Institute, Grasslands Research Centre, Private Bag 11008, Palmerston North 4442, New Zealand

e-mail: bryce.buddle@agresearch.co.nz

N. A. Parlane

e-mail: natalie.parlane@agresearch.co.nz health problem worldwide, costing US\$3 billion annually, with $>50$ million cattle infected [1]. Costs from this disease are related to a reduction in productivity in severely affected animals, testing, culling of affected animals, movement controls, and restriction on trade. Pasteurisation of milk and implementation of bovine TB control programmes coupled with abattoir surveillance have markedly reduced the transmission of $M$. bovis to humans, although risks remain with the consumption of unpasteurised milk and co-habitation of infected animals with humans.

The test and slaughter bovine TB control programmes which were introduced in many countries in the midtwentieth century achieved dramatic results and a number of countries were able to eradicate this disease. However, these test and slaughter control programmes have not been affordable or socially acceptable in many countries, and more than $94 \%$ of the world's population live in countries in which control of bovine TB in cattle or buffaloes is limited or absent [2]. Furthermore, the existence of wildlife reservoirs of $M$. bovis infection such as badgers in Great Britain and Ireland, brushtail possums in New Zealand, white-tailed deer in the USA, and wild boar in southern Spain [3] have frustrated attempts to eradicate the disease in cattle. New tools for control of bovine TB are urgently required, and development of effective vaccines against this disease would be very desirable.

An understanding of immunity to M. bovis infection of cattle can greatly benefit the rational design of new vaccines against bovine TB. In recent decades there has been a huge investment into research to control M. tuberculosis infection in humans, and many of the findings relating to the development of immunity and new vaccines are being applied to TB in cattle. Conversely, cattle can serve as a very valuable model for human TB. TB in cattle is a chronic disease with lesions located predominantly in the respiratory tract and associated lymph nodes. The kinetics of the disease can be easily followed by regular collection of large volumes of blood at relevant 
time points before and after vaccination and challenge with M. bovis. Also, neonatal calves are immunocompetent at birth and respond well to vaccines so use of this model is appropriate. In addition, cattle are an outbred, natural host for TB, and the impact of confounding factors such as exposure to parasites or environmental mycobacteria can be studied. The current review aims to provide an understanding of immunity against TB, with a particular emphasis on M. bovis infection in cattle and presents an update on the effectiveness of vaccines against bovine TB.

\section{Immunity against $M$. bovis Infection in Cattle}

The route of infection in cattle for the infectious bacterium, $M$. bovis, is predominantly by inhalation into the lungs or upper respiratory tract and is taken up by antigen presenting cells such as alveolar macrophages and dendritic cells. Primary infections can also result via oral ingestion of infected milk and uptake of $M$. bovis by $\mathrm{M}$ cells, and subsequently delivery to antigenpresenting cells in the lymphatics of the gastrointestinal tract. The pathogenesis of human and bovine TB is similar, and M. bovis and M. tuberculosis have evolved a range of mechanisms to evade the host responses. These include inhibition of phagosome maturation, interference with phagolysosome fusion, decrease in autophagy with subsequent decrease in antigen presentation [4], escape from the toxic environment of the phagosome, and alterations to cytokine responses.

Granulomas, the hallmark of mycobacterial disease, develop in response to chronic antigenic stimulation and aim to contain the mycobacterial infection. Encapsulation and phagocytosis by macrophages/giant cells may assist in the control of the infection, whereas neutrophils are a marker of bacterial proliferation during infection, as observed in asymptomatic, naturally infected cattle [5]. In experimentally infected cattle, granulomas can be observed microscopically as early as $7-15$ days after infection [6]. Detailed classification of granulomas into four stages has been described in calves, and infected lymph nodes may contain all four different stages at a single time point [7]. Stage 1 granulomas in the lymph nodes comprise infiltrations of epithelioid macrophages, lymphocytes, and small numbers of neutrophils, but no necrosis. Neutrophils phagocytose the mycobacteria, but despite activation and production of reactive oxygen intermediates, $M$. bovis is not readily killed, and instead the neutrophil is induced to apoptose or die by necrosis [8]. Yet neutrophils can play a protective role in the immune response by producing cytokines and chemokines necessary for the initiation of an adaptive immune response $[9,10]$. If bacteria are not killed by macrophages at this initial stage, then infection progresses. After Stage 1, the granuloma can then develop into Stage 2, with a solid mass comprising epithelioid macrophages, lymphocytes, neutrophils, and Langhans multinucleated giant cells enclosed by a thin capsule. A Stage 3 granuloma is fully encapsulated with a small-sized caseous mineralised central necrotic region surrounded by epithelioid macrophages and Langhans giant cells and a peripheral zone of lymphocytes and macrophages. Stage 4 granulomas have a thick, fibrous capsule, are larger in size, contain more bacteria, and have extensive caseous necrosis with mineralisation. This stage is characterised by multiple coalescing caseonecrotic granulomas. A recent comparison of gene expression of cytokines and immune mediators in the primary granuloma in the lung and in the draining pulmonary lymph nodes of $M$. bovis-infected cattle indicated a stronger pro-inflammatory immune response in the lung granulomas [11]. This may be a consequence of enhanced expression of interferon regulatory factor 5 (IRF5) promoting IFN- $\gamma$ and IL-17 production.

Cellular immunity is considered essential for clearance of mycobacterial infections, and macrophages are a key cell in this process. They are the main host for mycobacteria and also a key effector cell for control and killing the mycobacteria through lysosomal enzymes or reactive oxygen or nitrogen intermediates. Activation of macrophages can occur through different pathways with different outcomes (reviewed by [12, 13]). Classical activation of macrophages by IFN- $\gamma$ released by $\mathrm{T}$ lymphocytes leads to Th1 and Th17 type responses and more effective killing of the bacteria [14]. In contrast, alternative activation of macrophages occurs through stimulation with IL-4 or IL-13 which in turn generates a Th2 type response which down-regulates IFN- $\gamma$, increases arginase production which competes with iNOS for L-arginine, and therefore, low levels of nitrous oxide (NO) are produced resulting in less effective mycobacterial killing. Macrophages also express many diverse receptors that recognise mycobacteria; Mannose receptors bind mannosylated glycoproteins, complement receptors for $\mathrm{C} 3 \mathrm{~b}$ and $\mathrm{iC} 3 \mathrm{~b}$, and scavenger receptor binds low density lipoproteins. While binding can be demonstrated by these receptors, there is considerable compensation, leading to altering roles of receptors in anti-mycobacterial immunity during infection [15]. Binding of mycobacterial antigens to macrophages may lead to phagocytosis with lysosome fusion to create a phagolysosome. Mycobacterial breakdown products stimulate interleukin-1 receptor-associated kinase (IRAK), and combined with signalling from MyD88 leads to transcription of NFkB.

Toll-like receptors (TLRs) and Nod-like receptors (NLR) on antigen-presenting cells (APC) such as dendritic cells and macrophages are essential for mycobacterial recognition. Although they might not have an effect on initial mycobacterial growth and granuloma formation, TLR2, TLR4, TLR9, and NLR-2 bind with mycobacteria to initiate immune activation [16]. Recognition of mycobacteria through TLRs on APC leads to Myd88 activation and binding to IRAK. This effect activates NFkB to signal cytokine production. The expression of TLR2 genes was up-regulated more in $M$. bovis-stimulated cells from non-infected than infected cattle suggesting that this 
up-regulation could lead to a more efficient pro-inflammatory response [17]. Increased expression of IL-10 could be demonstrated in the infected cattle, which could down-regulate the pro-inflammatory immune response, decreasing the ability of macrophages to restrict mycobacterial growth.

Dendritic cells (DC) are potent APC which recognise and take up foreign antigens and then migrate to lymph nodes to present processed antigen to T cells. Bovine DC and macrophages respond to infection with $M$. bovis providing some interesting similarities and differences [18]. Both DC and macrophages were able to phagocytose $M$. bovis, but the bacteria were able to grow in both cells even though macrophages were able to kill more organisms than DC. Pre-stimulation with IFN- $\gamma$ resulted in more killing of $M$. bovis by DC, but only to the same level as killing by macrophages and live bacteria still remain. BCG is able to be killed to a greater extent by both cells compared to that for virulent $M$. bovis. Cytokine secretion was also measured in the same study, which showed that IL-12 is secreted by M. bovis-infected DC and in lesser amounts by macrophages. The difference may be linked to the increased number of bacteria in the DC. IL-12 secretion by DC is essential to activate NK cells to release IFN- $\gamma$. IL-10 is also secreted by DC and macrophages, and in another study, macrophages were shown to secrete significantly more IL-10 than DC [19]. TNF- $\alpha$ was secreted by both DC and macrophages, which is considered to be important in amplifying killing by macrophages and DC. M. bovis-infected DC were able to up-regulate the expression of MHC II and CD80, but less so for macrophages. MHC I was up-regulated in both types of cells. Overall, DC appear to be more efficient at stimulating $\mathrm{T}$ cell responses and macrophages are more effective at killing the mycobacteria.

NK cells are large granular lymphocytes that are thought to bridge the gap between innate and adaptive immunity. Cattle express the NK cell marker NKp46 with a frequency of $0.5-$ $10 \%$ blood lymphocytes. They rapidly produce cytokines including IFN- $\gamma$, which serves to activate macrophages for enhanced killing of bacteria [20]. M. bovis-infected DC release chemokines to preferentially recruit the $\mathrm{NKp} 46^{+} \mathrm{CD}^{-}$population of NK cells with subsequent activation of these cells. NK cells are also cytotoxic through the release of perforin and granulysin leading to killing of $M$. bovis-infected APCs [21-23]. Release of perforin is attained both in association with and without DC involvement [24]. These experiments showed that cell-cell contact is necessary to result in both NK cell activation leading to release of IFN- $\gamma$ and also DC activation as measured by an increase in MHCII expression. A recent paper has demonstrated a small population of $\mathrm{NKp}_{4} 6^{+} \mathrm{CD}^{+}$ bovine cells in normal bovine blood with a frequency of $0.1-$ $1.7 \%[25 \cdot \bullet]$, but experiments have yet to be done to determine if this population of cells responds to mycobacterial challenge.

$\mathrm{T}$ helper $\mathrm{CD} 4{ }^{+} \mathrm{T}$ cells are the predominant cell type responsible for producing a robust IFN- $\gamma$ response, which is important for promoting adaptive immunity, while IFN- $\gamma$ is also produced by $\mathrm{CD} 8^{+} \mathrm{T}$ cells, $\gamma \delta \mathrm{T}$ cells, and NK cells $[26$, 27]. Cytolysis of mycobacteria-infected cells has been shown to result in direct killing of the bacilli or release of bacilli for eventual killing by other mechanisms [28]. The primary cell type performing this function is the $\mathrm{CD} 8^{+} \mathrm{T}$ cell. Also, other cells which have this cytolytic capacity include NK cells, $\mathrm{CD}^{+} \mathrm{T}$ cells, and $\gamma \delta \mathrm{T}$ cells $[22,29]$.

$\gamma \delta$ T cells represent $10-20 \%$ of circulating T cells in adult cattle, but up to $55 \%$ in newborn calves compared to just $1-$ $10 \%$ in adult humans [30]. They can be classified according to expression of $\mathrm{WC1}$ receptor, with the principal bovine $\gamma \delta \mathrm{T}$ cells in the circulation being $\mathrm{WC}^{+}{ }^{+} \mathrm{CD} 2^{-} \mathrm{CD} 4^{-} \mathrm{CD} 8^{-}$. The cells have both an innate and adaptive activity. $\gamma \delta$ T cells respond to a variety of antigens including non-peptide antigens [31], pathogen-associated molecular patterns (PAMPs), and dangerassociated molecular patterns (DAMPs) such as stress protein [32]. In calves challenged with M. bovis, this cell population translocates from the blood to the site of infection and can be demonstrated in granulomas [33]. The circulatory population then rapidly expands and shows an activated profile with increased $\mathrm{CD} 25^{+}$expression. The cells have been shown to be cytotoxic [34] and express perforin [35] and granulysin [22]. Contact dependant interactions between DC and $\mathrm{WC}^{+} \gamma \delta$ cells have demonstrated that DC induce activation of $\mathrm{WC}^{+} \gamma \delta$ cells which leads to IFN- $\gamma$ release [36]. Another role of $\mathrm{WCl}^{+} \gamma \delta$ cells is antigen presentation, and a recent study showed that following stimulation with BCG, peripheral blood-derived $\gamma \delta$ cells were able to express APC-associated molecules, MHC II, and $\mathrm{CD} 80$ [32]. It has also been proposed that bovine $\mathrm{WC1}^{+} \gamma \delta$ cells are the major regulatory $\mathrm{T}$ cell subset in peripheral blood. Depletion of WCI $+\gamma \delta$ cells from M. bovis-infected cattle had no effect on granuloma or disease severity, although immune responses were skewed to a Th2 type immune response, indicating that these cells may have regulatory function [37]. More recently, the regulatory role of $\gamma \delta \mathrm{T}$ cells has been highlighted by these cells spontaneously secreting IL-10 and proliferating in response to IL-10, TGF- $\beta$, and contact with APCs [38•].

In summary, innate inflammatory responses, mediated by macrophages, neutrophils, $\gamma \delta \mathrm{T}$ lymphocytes, and NK cells, are able to reduce or even eliminate early TB infection. As a counter measure mycobacteria have developed ways to obstruct innate cell's signalling TLRs and other mediators of innate immunity and to hinder the maturation of phagosomes in infected macrophages. The innate cell types interact with each, but also with the adaptive immune system. They can "license" antigen-presenting cells, particularly DC, to become more efficient stimulators of $\mathrm{T}$ lymphocytes specific for different antigens and induce stronger cytolytic and proliferative responses. Hence, effective vaccination against TB should include stimulation of innate cells like NK cells and $\gamma \delta$ T cells by protein and non-protein mycobacterial compounds which will provide aid to developing innate as well as adaptive TB responses. 


\section{Vaccination against Bovine TB in Cattle}

Currently, there is renewed interest in the use of TB vaccines for cattle from the realisation of the financial impact of bovine TB on animal health and trade and due to the difficulty controlling the disease. Although TB vaccines are not presently licensed for use in cattle, there have been a number of new recent developments in TB vaccines for cattle (highlights listed in Table 1). The major caveats which have restricted the use of TB vaccines in cattle until now have been that protection may not be complete and vaccination sensitises animals to respond in traditional TB diagnostic tests. Potentially, these issues can now be overcome by using vaccination as part of a control programme integrated with other control measures and using diagnostics tests that can differentiate infected from vaccinated animals (DIVA tests).

\section{Vaccination with Mycobacterium bovis Bacille Calmette-Guérin (BCG)}

BCG vaccine, the only TB vaccine licensed for use in humans, has advantages for use in cattle since the vaccine is safe, inexpensive, is commercially produced for human application, and DIVA tests are available. Calmette and Guérin first reported in 1911 that high doses of BCG $(20 \mathrm{mg})$ could induce protection in cattle against experimental challenge with $M$. bovis, and trials were undertaken in a number of different countries in the early twentieth century to determine efficacy of BCG vaccine in cattle (reviewed in $[1,53]$ ). While studies investigating protection against experimental challenge provided encouraging results, the majority of results produced in field trials were disappointing. With an increased understanding of immunity to $\mathrm{TB}$, a number of different explanations may now explain the variable levels of protection observed in field trials. These include the use of different BCG strains, very high doses of BCG administered, pre-existing exposure to environmental mycobacteria, lack of long-term protection, very high levels of natural challenge, and $M$. bovis exposure from milk of infected cows prior to vaccination. The variable levels of protection observed in field trials mirrors the situation in humans where BCG vaccine efficacy against pulmonary TB in children and adults is highly variable, ranging from 0 to $80 \%$ [54].

Over the past two decades, a large amount of knowledge has been acquired on the use of BCG through the harmonisation of cattle challenge models, BCG strains, and doses. Challenge models have more recently focused on using a challenge dose of $10^{3}$ to $10^{4}$ colony forming units (CFU) of $M$. bovis administered by intratracheal/endobronchial inoculation or aerosol, reproducing the common manifestations of the natural disease in the lower respiratory tract and allowing for a more reproducible scoring of pathology [39, 46••, 55]. Protection is assessed by quantitative gross, histopathological, and microbiological findings between vaccinated and control groups of animals. Against experimental challenge with $M$. bovis, vaccination with BCG via subcutaneous or oral routes has repeatedly resulted in reductions in pathological and microbiological findings, although sterilising immunity is not produced. The experimental challenge is more severe than that observed following natural exposure as it is aimed to produce pathology in the majority of the non-vaccinated animals, while mimicking the pathology observed in naturally-infected cattle.

BCG vaccine has been shown to be effective when administered at relatively low doses $\left(10^{3}\right.$ to $\left.10^{6} \mathrm{CFU}\right)$ subcutaneously [39] or at higher doses $\left(10^{8} \mathrm{CFU}\right)$ via the oral route [56], and by different daughter BCG strains (Pasteur and Danish) [57, 58]. Vaccination of neonatal calves $(<1$ month of age) induced higher levels of protection than those vaccinated at 6 months of age $[42,43]$. This may be explained by the high numbers of circulating NK and $\gamma \delta$ T cells in young calves which may lead to a robust innate response following vaccination and administration of BCG prior to presensitisation with environmental mycobacteria. Prior sensitisation with environmental mycobacteria has been reported to prevent induction of

Table 1 Recent highlights in development of TB vaccines for cattle

\begin{tabular}{|c|c|c|}
\hline Year & Development & References \\
\hline 1995 & Low doses of parenteral BCG protected against bovine TB. & [39] \\
\hline 1999-2001 & Use of specific $M$. bovis antigens in whole blood IFN- $\gamma$ test could differentiate BCG-vaccinated from $M$. bovis-infected cattle. & {$[40,41]$} \\
\hline 2003-2005 & BCG vaccine induced a high efficacy in calves $<1$ month old. & {$[42,43]$} \\
\hline 2003-2005 & Combinations of TB DNA or protein vaccine with BCG induced protection greater than with BCG alone. & {$[44,45]$} \\
\hline 2009 & BCG prime with viral vector vaccine boost enhanced protection against bovine TB. & {$[46 \bullet \bullet$} \\
\hline 2009 & Vaccine-induced central memory immune response was a useful correlate of protection. & {$[46 \bullet \bullet, 47]$} \\
\hline 2010 & DIVA skin test was developed for differentiation of BGC-vaccinated from $M$. bovis-infected cattle. & {$[48 \bullet \bullet]$} \\
\hline 2011 & Demonstrated that maintenance of antigen-specific skin test response was not required for protection. & [49] \\
\hline 2012 & BCG-induced immunity waned between 12-24 months post-vaccination. & {$[50 \bullet]$} \\
\hline 2012 & BCG strain overexpressing Ag85B induced better protection than that induced by wild-type BCG strain. & {$[51 \bullet]$} \\
\hline 2014 & Revaccination with BCG when immunity had waned boosted protection against bovine $\mathrm{TB}$. & {$[52 \bullet \bullet]$} \\
\hline
\end{tabular}


protection induced by BCG in calves [59], while in another study there was evidence that $M$. avium exposure induced a level of protection against experimental M. bovis infection, possibly masking subsequent immunity induced by BCG [60]. A recent study demonstrated that BCG immunity may not be of long duration, with protection induced in calves vaccinated at 1 month of age and challenged 12 months later, while no significant protection was observed in another cohort challenged after 24 months [50 ${ }^{\bullet}$. This raises an important question whether BCG immunity can be boosted by revaccination.

Calves vaccinated as neonates and then revaccinated 6 weeks later had significantly reduced protection compared to those vaccinated once as neonates [42]. The revaccinated calves which were not protected had the strongest antigenspecific peripheral blood IFN- $\gamma$ responses at the time of revaccination, implying that the BCG was still actively proliferating in these animals and BCG revaccination may be contraindicated in the face of strong pre-existing immune response. A recent study has demonstrated that BCG revaccination of cattle at 2 years after initial vaccination when immunity had waned boosted protection against challenge with M. bovis. In contrast, revaccination with either of two TB protein vaccines failed to enhance protection [52••]. This study provided encouragement that protection could be produced in cattle following revaccination with $\mathrm{BCG}$ at 2 years after initial vaccination, and further studies are now required to optimise the timing of revaccination to provide long-term protection and to evaluate revaccination in the field situation.

Field trials in Mexico, Ethiopia, and New Zealand have provided evidence for BCG to protect against natural exposure to M. bovis. A group of calves in Mexico were vaccinated with BCG subcutaneously at 2 weeks of age and together with an equivalent age group of non-vaccinated calves were mixed with TB reactor cows for a 12 month period [61]. A positive case of TB was defined as an animal that had a positive reaction to the three following tests: tuberculin skin test, IFN- $\gamma$ PPD-B, and IFN- $\gamma$ ESAT-6/CFP10 during the previous 12 months. There were significantly fewer BCG-vaccinated animals positive for TB than that for the non-vaccinated group. In Ethiopia, a group of calves were vaccinated with BCG subcutaneously, and 3 months later these animals and a group of control calves were mixed with TB reactor cattle for a total of $10-22$ months. Following slaughter of the animals, the BCG-vaccinated animals were found to have significantly fewer animals with gross pathology or culture-positive for $M$. bovis compared to that for the control group [62•]. A BCG field trial has just been completed on an isolated farm in New Zealand where M. bovis infection was endemic in wildlife (possums, ferrets, wild pigs, and wild deer). Over a 3-year period, five cohorts of cattle (ranging from 6 to 30 months of age) were tuberculin skin tested and reactor animals excluded from the study, but retained in the herd. Just over half of the almost 1,300 test-negative cattle were vaccinated orally with BCG mixed in a lipid matrix
(Liporale, University of Otago, New Zealand), and the remainder left unvaccinated. These cattle were subsequently slaughtered at a commercial slaughterhouse when they reached their target weight for beef animals at $3-4$ years of age. An oral (rather than injected) preparation of BCG was used as it was considered likely to produce fewer BCG-induced positive skin test responses in tests conducted a year or more after vaccination. At the slaughterhouse, the animals were examined for tuberculous lesions and samples collected for bacterial culture. Of $>1,200$ animals inspected, preliminary analysis indicated that a significantly smaller percentage $(\sim 4 \%)$ of vaccinated animals were infected with $M$. bovis compared with $\sim 10 \%$ for the non-vaccinated animals (G. Nugent, personal communication). The efficacy of the vaccine appeared to be high in the first year after vaccination.

\section{New TB Vaccines Evaluated in Cattle}

In the last two decades, large amounts of funding have been provided to identify effective human TB vaccines and many of these vaccines are now in human clinical trials. Efforts to develop and evaluate new TB vaccines for cattle have greatly benefited from this research. The different types of TB vaccines which have recently been tested in cattle include live attenuated mycobacteria which could replace BCG and subunit TB vaccines such as DNA, protein, and virus-vectored vaccines which could be used to boost immunity induced by BCG (summarised in Table 2).

Published reports evaluating live attenuated mycobacterial vaccines in cattle have included modified BCG strains, an M. bovis auxotroph, and deletion mutants of M. tuberculosis and M. bovis. A BCG strain has been developed which overexpressed Ag85B and cattle vaccinated with this strain had significantly lower histopathological lesion scores for the lungs following challenge with $M$. bovis than those vaccinated with the parent BCG strain [51•]. Another modification of BCG has been the deletion of the zmpl gene, based on the concept the mycobacterial Zmp1 inhibited phagolysosome maturation by preventing inflamasome activation. A consequence may be that mycobacterial antigens are not efficiently presented by MHC class I and II antigens. Vaccination of cattle with either of two BCG zmpl deletion strains resulted in superior T cell memory responses induced by both strains compared to animals vaccinated with a wild-type BCG strain [63]; however, a trial to assess the efficacy of this vaccine has yet to be reported. Calves vaccinated with a leucine auxotroph of $M$. bovis were shown to have a significantly reduced bacterial burden and histopathology following challenge with virulent $M$. bovis, compared to non-vaccinated controls [65]. A comparison with BCG was not undertaken in this study. A double deletion mutant of M. tuberculosis, a region of difference 1 (RD1) knockout, and pantothenate auxotroph failed to protect calves from a low 
Table 2 New TB vaccines tested in cattle

\begin{tabular}{|c|c|c|c|}
\hline Type of Vaccine & Vaccine & $\begin{array}{l}\text { Protection against } \mathrm{TB} \\
\text { compared to } \mathrm{BCG}\end{array}$ & Reference \\
\hline \multirow[t]{2}{*}{ Modified BCG } & BCG overexpressing Ag85B & + & {$[51 \cdot]$} \\
\hline & BCG $\Delta \mathrm{zmp} 1$ & NT & {$[63]$} \\
\hline Attenuated $M$. tuberculosis strain & M. tuberculosis $\triangle \mathrm{RD} 1 \Delta \mathrm{panCD}$ & - & {$[64]$} \\
\hline \multirow[t]{4}{*}{ Attenuated $M$. bovis strain } & UV-irradiated M. bovis & + & {$[59]$} \\
\hline & M. bovis $\Delta$ leuD & $\mathrm{NT}^{\mathrm{a}}$ & {$[65]$} \\
\hline & M. bovis $\Delta \mathrm{RD} 1$ & $=$ & {$[47]$} \\
\hline & M. bovis $\Delta$ mce2 & + & {$[66]$} \\
\hline \multirow[t]{2}{*}{ DNA vaccine } & Mycobacterial DNA & $=$ & {$[67,68]$} \\
\hline & Mycobacterial DNA + BCG & + & {$[44,69,70]$} \\
\hline \multirow[t]{2}{*}{ Adjuvanted protein vaccine } & Protein + BCG & + & {$[45,71]$} \\
\hline & Protein + BCG & $=$ & {$[72]$} \\
\hline Virus-vector vaccine & $\begin{array}{l}\text { BCG + recombinant adenovirus or vaccinia } \\
\text { virus expressing mycobacterial protein }\end{array}$ & + & {$[46 \bullet \bullet, 72]$} \\
\hline
\end{tabular}

NT Not tested against TB challenge or compared with BCG

${ }^{\text {a }}$ Significant protection against TB, but not tested against BCG

+ Significantly better than BCG

$=$ Equivalent protection to $\mathrm{BCG}$

- No protection against TB

dose, aerosol M. bovis challenge [64]. In contrast, vaccination of calves with an RD1 deletion mutant of $M$. bovis provided protection comparable to BCG [47]. For cattle, an attenuated M. tuberculosis mutant may be less immunogenic as compared to those produced on an M. bovis or BCG background strain as cattle are not common hosts for M. tuberculosis infections. Vaccination with either of two attenuated $M$. bovis strains derived by UV irradiation, with deletions not defined, produced significant protection against challenge with $M$. bovis in calves naturally pre-sensitised to environmental mycobacteria, in a study where BCG vaccine was shown to be ineffective [59]. An attenuated M. bovis strain with a double deletion in the $m c e 2$ gene was shown to induce significant protection against an $M$. bovis challenge and induced significantly lower histopathological scores for the lungs and pulmonary lymph nodes compared to that for BCG [66]. Use of the modified BCG strains or RD1 mutants of $M$. bovis has the advantage that vaccinated animals can be differentiated from $M$. bovis-infected animals using DIVA tests, while this could not be achieved for those vaccinated with the $M$. bovis mce 2 deletion mutant.

It has proved difficult to induce protection against $M$. bovis infection with sub-unit TB vaccines, although they can produce a synergistic effect when used in combination with BCG vaccine. DNA vaccines have induced minimal protection against TB when used alone, although some protection has been observed when mycobacterial DNA was combined with DNA encoding co-stimulatory molecules CD80 and CD86 [67] or combined with an adjuvant [68]. More encouraging results have been reported when DNA vaccines have been used in heterologous prime-boost regimes with BCG, and priming or boosting with mycobacterial DNA vaccines induced greater protection than with BCG vaccine alone [44, $69,70]$. Similarly, TB protein vaccines have induced little protection in cattle when used alone, whereas when coadministered at adjacent sites with BCG have induced protection that was better than that observed with BCG alone [45, 71]. The major problem encountered using TB protein vaccines in cattle has been the difficulty of inducing strong cellular immune responses with these vaccines, despite coadministering with a wide range of toll-like receptors (TLR) agonists including, TLR2 (Pam3Cys, Pam3CSK4), TLR4 (Lipid A, glucopyranosyl lipid A), TLR 7/8 (Resiquimod), and TLR 9 (CpG oligonucleotides) [45, 52••, 71, 73]. Finally, priming with BCG and boosting with human TB virus vector vaccines expressing mycobacterial proteins have shown considerable promise. Priming with BCG and boosting with either modified vaccinia virus Ankara expressing Ag85A or replication deficient adenovirus 5 (Ad5) expressing Ag85A resulted in protection superior to that with $B C G$ alone $[46 \bullet \cdot]$. In a recent study, BCG-vaccinated calves were boosted with either Ad5 expressing Ag85A (Ad5-85A) or Ag85A, Rv0287, Rv0288, and Rv0251 (Ad5-TBF), or with four recombinant proteins, Ag85A, Rv0287, Rv0288, and Rv0251 mixed in an adjuvant. No increase in protection compared to BCG alone was afforded by boosting with the different vaccines when assessed by gross pathology and bacteriology; however, boosting BCG with Ad5-85A induced a significantly lower histopathological lesion score than that for those vaccinated 
with BCG alone [72]. From an immunogenicity study, the optimal dose and route of immunisation of the Ad5-85A used as a boost following a BCG prime was determined to be $2 \times$ $10^{9}$ infectious units delivered intradermally [74].

\section{Correlates of Vaccine Efficacy or Disease}

There is no single correlate of protection for TB, although a number of immune parameters have shown promise in this regard. However, it is still necessary to challenge animals to determine vaccine efficacy and disease. IFN- $\gamma$ responses by $\mathrm{T}$ cells are strongly induced following infection and are often measured as an indicator of disease [75]; however, this parameter is less certain as a correlate of vaccine efficacy. Early IFN- $\gamma$ responses are required post-vaccination, so the timing of testing is important and the amount of IFN- $\gamma$ does not always correlate with protection [57]. Increasing ESAT-6/ CFP10-specific IFN- $\gamma$ responses post-challenge are a negative indicator of vaccine efficacy and positively correlated with TBassociated pathology $[64,76]$. Antigen-specific post-vaccination $\mathrm{T}$ cell central memory $(\mathrm{Tcm})$ immune responses can be measured 12 weeks post-vaccination using a Cultured ELIS POT technique and serve as a positive predictor of vaccine efficacy [46••, 47, 77]. IL-17 responses to mycobacterial antigen have also been used as a positive predictor of vaccine efficacy post-vaccination, while post-challenge, IL-17 expression correlated with disease severity $[44,56]$. A population of poly-functional T cells that simultaneously release IFN- $\gamma$, IL-2, and TNF- $\alpha$ have recently been investigated from cattle naturally infected with $M$. bovis and revealed that these $\mathrm{CD} 4^{+} \mathrm{T}$ cells express a $\mathrm{CD} 44^{\mathrm{hi}} \mathrm{CD} 45 \mathrm{RO}^{+} \mathrm{CD} 62 \mathrm{~L}^{\text {lo }}$ T-effector memory (TEM) phenotype which is associated with pathology [78]. The assessment of polyfunctional $T$ cells following vaccination still needs to be determined. A recent study has shown that cattle producing IL-2 and IFN- $\gamma$ (measured by ELISA from antigenstimulated blood cultures) were more likely to have visible pathology post-challenge than those that only produced IFN- $\gamma$ [79]. Detection of a delayed type-hypersensitivity (DTH) response to tuberculin is used as the primary screening tool for detection of TB in cattle, although there is not a consistent correlation with protection post-vaccination. Most effective vaccines elicit a DTH response, and non-sensitising vaccines such as low oral doses of BCG have not been shown to induce protection [56], although maintenance of a DTH response is not linked with protection [49]. Serological responses to mycobacterial antigens have not been linked with protection post-vaccination as shown when TB protein vaccines were used alone, whereas when TB protein vaccines are used concurrently with a BCG vaccine, protection was not adversely affected by the induction of an antibody response [45]. There have been numerous attempts to detect $M$. bovis infection in cattle using serology, and generally, test sensitivity has been low compared to that for cellular immune responses, although there may be a link between severity of disease and induction of an antibody response [75].

\section{DIVA Tests}

Vaccination with TB vaccines can compromise the interpretation of the tuberculin skin test, and up to $80 \%$ of BCGvaccinated calves have been shown to react in the tuberculin skin test at 6 months post-vaccination [49]. Encouragingly, this decreased to $10-20 \%$ by 9 months post-vaccination and protection against TB was not dependent on maintenance of a tuberculin skin test response. However, it is still important to develop DIVA tests to differentiate animals vaccinated with BCG from those infected with $M$. bovis. DIVA tests have now been developed using antigens from the M. tuberculosis complex which are not expressed or secreted by BCG and can be used instead of bovine PPD in the skin test [48 $\bullet$ ] or in the whole blood IFN- $\gamma$ release assay (reviewed by [80]). The first two antigens used in DIVA tests were the early secreted antigen target $6 \mathrm{kDa}$ protein (ESAT-6) and culture filtrate protein 10 (CFP10) which are encoded in the RD1 of M. bovis and M. tuberculosis. Following comparative transcriptome analysis of Mycobacterium species, a further protein, Rv3615c, was added to DIVA tests to enhance sensitivity, while not being recognised by non-infected or BCG-vaccinated cattle [81]. Although Rv3615c is not located in the RD1 region of the $M$. bovis genome, its secretion is dependent on the esx-1 secretion system located in the RD1 region. A recent assessment of the whole blood IFN- $\gamma$ DIVA test incorporating ESAT-6, CFP10, and Rv3615c antigens was undertaken in 75 BCGvaccinated, M. bovis-infected cattle and 179 BCG-vaccinated, non-infected animals, revealing estimates of $96.0 \%$ sensitivity and $95.53 \%$ specificity [82].

A cost-effective strategy to use the DIVA IFN- $\gamma$ test would be to apply the test on tuberculin skin test-reactor cattle. An alternative approach would be to use antigens from these proteins in a primary screening skin test. Such a refined skin test has been shown to have a high sensitivity for $M$. bovis-infected animals, while not compromised by BCG vaccination or vaccination against Johne's disease [48 $\bullet, 83]$. A potential problem with the use of these antigens in a primary screening skin test would be the cost of the reagents. A recent study has shown that these antigens could be displayed on polyester inclusion bodies produced in bacteria such as Escherichia coli (Biobeads), producing a skin test reagent with a high sensitivity and specificity [84]. The cost of production of these Biobeads displaying a fusion protein of these three proteins is markedly lower than that of recombinant proteins or peptides as the antigens are used at very low concentrations due to their high immunogenicity and they are produced by fermentation technology. 


\section{Conclusions}

Interest in development and use of TB vaccines for cattle has been rekindled with an improved understanding of protective immunity against TB, development of tests to differentiate infected from vaccinated animals, and the huge investment into the development of TB vaccines for humans. From the evaluation of a range of different $\mathrm{TB}$ vaccines in cattle, no single vaccine has clearly been shown to be superior to BCG, although small improvements have been seen following vaccination with some attenuated mycobacterial vaccines as well as combinations of sub-unit vaccines and BCG. It is clear that protection induced by BCG vaccine wanes in cattle with time and it is important that protection can be enhanced by revaccination with BCG when immunity has waned. The development and use of DIVA tests will be essential in developed countries which export cattle and cattle products as vaccination is unlikely to induce complete protection, while in many developing countries vaccination without DIVA tests could be useful for reducing the spread of $M$. bovis in cattle. In both situations, vaccination should be used in association with a range of other control strategies. Many variables may affect the efficacy of TB vaccines in the field and it is essential that field trials are undertaken in the near future to establish the role of TB vaccines in control programmes and the economics of such an approach.

Acknowledgements The authors thank Drs. Axel Heiser and Geoff de Lisle for helpful review of the manuscript and the New Zealand Ministry of Business, Innovation, and -Employment for funding.

\section{Compliance with Ethics Guidelines}

Conflict of Interest Dr. Parlane and Dr. Buddle are inventors of a patent to display mycobacterial antigens on polyester inclusions as vaccines or skin test reagents. Both Dr. Parlane and Dr. Buddle received funding from the New Zealand Ministry of Business, Innovation, and Employment for funding.

Dr Buddle is an inventor on a patent for an oral formulation of BCG vaccine.

Human and Animal Rights and Informed Consent This article contains no studies with human or animal subjects performed by any of the authors.

\section{References}

Papers of particular interest, published recently, have been highlighted as:

- Of importance

- Of major importance

1. Waters WR, Palmer MV, Buddle BM, Vordermeier HM. Bovine tuberculosis vaccine research: historical perspectives and recent advances. Vaccine. 2012;30(16):2611-22.
2. Cousins DV. Mycobacterium bovis infection and control in domestic livestock. Rev Sci Tech. 2001;20(1):71-85.

3. de Lisle GW, Bengis RG, Schmitt SM, O'Brien DJ. Tuberculosis in free-ranging wildlife: detection, diagnosis and management. Rev Sci Tech Off Int Epiz. 2002;21(2):317-34.

4. Harris J, Master SS, De Haro SA, Delgado M, Roberts EA, Hope $\mathrm{JC}$, et al. Th1-Th2 polarisation and autophagy in the control of intracellular mycobacteria by macrophages. Vet Immunol Immunopathol. 2009;128(1-3):37-43.

5. Menin Á, Fleith R, Reck C, Marlow M, Fernandes P, Pilati C, et al. Asymptomatic cattle naturally infected with Mycobacterium bovis present exacerbated tissue pathology and bacterial dissemination. PLoS One. 2013;8(1):e53884.

6. Cassidy JP, Bryson DG, Pollock JM, Evans RT, Forster F, Neill SD. Early lesion formation in cattle experimentally infected with Mycobacterium bovis. J Comp Pathol. 1998;119(1):27-44.

7. Wangoo A, Johnson L, Gough J, Ackbar R, Inglut S, Hicks D, et al. Advanced granulomatous lesions in Mycobacterium bovis-infected cattle are associated with increased expression of Type I procollagen, $\gamma \delta(\mathrm{WC} 1+) \mathrm{T}$ cells and CD $68+$ cells. J Comp Pathol. 2005;133(4):223-34.

8. Wang J, Zhou X, Pan B, Yang L, Yin X, Xu B, et al. Investigation of the effect of Mycobacterium bovis infection on bovine neutrophils functions. Tuberculosis. 2013;93(6):675-87.

9. Sawant KV, Cho H, Lyons M, Ly LH, McMurray DN. Guinea pig neutrophil-macrophage interactions during infection with Mycobacterium tuberculosis. Microb Infect. 2010;12(11):828-37.

10. Sawant KV, McMurray DN. Guinea pig neutrophils infected with Mycobacterium tuberculosis produce cytokines which activate alveolar macrophages in noncontact cultures. Infect Immun. 2007;75(4):1870-7.

11. Shu D, Heiser A, Wedlock DN, Luo D, de Lisle GW, Buddle BM. Comparison of gene expression of immune mediators in lung and pulmonary lymph node granulomas from cattle experimentally infected with Mycobacterium bovis. Vet Immunol Immunopathol. 2014;160(1-2):81-9.

12. Gordon S. Alternative activation of macrophages. Nat Rev Immunol. 2003;3(1):23-35.

13. Gordon S, Martinez FO. Alternative activation of macrophages: mechanism and functions. Immunity. 2010;32(5):593-604.

14. Denis M, Wedlock DN, Buddle BM. IFN- $\gamma$ enhances bovine macrophage responsiveness to Mycobacterium bovis: Impact on bacterial replication, cytokine release and macrophage apoptosis. Immunol Cell Biol. 2005;83(6):643-50.

15. Schäfer G, Guler R, Murray G, Brombacher F, Brown GD. The role of scavenger receptor B1 in infection with Mycobacterium tuberculosis in a murine model. PLoS One. 2009;4(12):e8448.

16. Walter K, Hölscher C, Tschopp J, Ehlers S. NALP3 is not necessary for early protection against experimental tuberculosis. Immunobiology. 2010;215(9-10):804-11.

17. Wang Y, Zhou X, Lin J, Yin F, Xu L, Huang Y, et al. Effects of Mycobacterium bovis on monocyte-derived macrophages from bovine tuberculosis infection and healthy cattle. FEMS Microbiol Lett. 2011;321(1):30-6.

18. Hope JC, Thom ML, McCormick PA, Howard CJ. Interaction of antigen presenting cells with mycobacteria. Vet Immunol Immunopathol. 2004;100(3-4):187-95.

19. Denis M, Buddle BM. Bovine dendritic cells are more permissive for Mycobacterium bovis replication than macrophages, but release more IL-12 and induce better immune T-cell proliferation. Immunol Cell Biol. 2008;86(2):185-91.

20. Denis M, Keen DL, Parlane NA, Storset AK, Buddle BM. Bovine natural killer cells restrict the replication of Mycobacterium bovis in bovine macrophages and enhance IL-12 release by infected macrophages. Tuberculosis (Edinb). 2007;87(1):53-62. 
21. Lu C-C, Wu T-S, Hsu Y-J, Chang C-J, Lin C-S, Chia J-H, et al. NK cells kill mycobacteria directly by releasing perforin and granulysin. J Leukoc Biol. 2014. doi:10.1189/ jlb.4A0713-363RR.

22. Endsley JJ, Furrer JL, Endsley MA, McIntosh MA, Maue AC, Waters WR, et al. Characterization of bovine homologues of granulysin and NK-lysin. J Immunol. 2004;173(4):2607-14.

23. Capinos Scherer CF, Endsley JJ, De Aguiar JB, Jacobs Jr WR, Larsen MH, Palmer MV, et al. Evaluation of granulysin and perforin as candidate biomarkers for protection following vaccination with Mycobacterium bovis BCG or M. bovis $\triangle \mathrm{RD} 1$. Transbound Emerg Dis. 2009;56(6-7):228-39.

24. Siddiqui N, Hope J. Differential recruitment and activation of natural killer cell sub-populations by Mycobacterium bovis-infected dendritic cells. Eur J Immunol. 2013;43(1):159-69.

25.• Connelly TK, Longhi C, Burrells A, Degnan K, Hope J, Allan AJ, et al. NKp461+CD3+ cells: A novel nonconventional T cell subset in cattle exhibiting both NK cell and T Cell features. J Immunol. 2014;192(8):3868-80. Discusses the Tcell functions of NK cells.

26. Pollock JM, McNair J, Welsh MD, Girvin RM, Kennedy HE, Mackie DP, et al. Immune responses in bovine tuberculosis. Tuberculosis. 2001;81(1-2):103-7.

27. Endsley JJ, Waters WR, Palmer MV, Nonnecke BJ, Thacker TC, Jacobs Jr WR, et al. The calf model of immunity for development of a vaccine against tuberculosis. Vet Immunol Immunopathol. 2009;128(1-3):199-204.

28. Flynn JL, Chan J. Immunology of tuberculosis. Annu Rev Immunol. 2001;19(1):93-129.

29. Stenger S, Hanson DA, Teitelbaum R, Dewan P, Niazi KR, Froelich $\mathrm{CJ}$, et al. An antimicrobial activity of cytolytic T cells mediated by granulysin. Science. 1998;282(5386):121-5.

30. Wyatt CR, Madruga C, Cluff C, Parish S, Hamilton MJ, Goff W, et al. Differential distribution of $\gamma \delta \mathrm{T}$-cell receptor lymphocyte subpopulations in blood and spleen of young and adult cattle. Vet Immunol Immunopathol. 1994;40(3):187-99.

31. Pollock JM, Welsh MD. The $\mathrm{WC1}^{+} \gamma \delta \mathrm{T}$-cell population in cattle: a possible role in resistance to intracellular infection. Vet Immunol Immunopathol. 2002;89(3-4):105-14.

32. Guzman E, Price S, Poulsom H, Hope J. Bovine $\gamma \delta$ T cells: cells with multiple functions and important roles in immunity. Vet Immunol Immunopathol. 2012;148(1-2):161-7.

33. Cassidy JP, Bryson DG, Gutiérrez Cancela MM, Forster F, Pollock JM, Neill SD. Lymphocyte subtypes in experimentally induced earlystage bovine tuberculous lesions. J Comp Pathol. 2001;124(1):46-51.

34. Skinner MA, Parlane N, McCarthy A, Buddle BM. Cytotoxic T-cell responses to Mycobacterium bovis during experimental infection of cattle with bovine tuberculosis. Immunology. 2003;110(2):234-41.

35. Alvarez AJ, Endsley JJ, Werling D, Mark Estes D. WC $1+\gamma \delta$; T cells indirectly regulate chemokine production during Mycobacterium bovis infection in SCID-bo mice. Transbound Emerg Dis. 2009;56(6-7):275-84.

36. Price SJ, Hope JC. Enhanced secretion of interferon- $\gamma$ by bovine $\gamma \delta$ $\mathrm{T}$ cells induced by coculture with Mycobacterium bovis-infected dendritic cells: evidence for reciprocal activating signals. Immunology. 2009;126(2):201-8.

37. Kennedy HE, Welsh MD, Bryson DG, Cassidy JP, Forster FI, Howard CJ, et al. Modulation of immune responses to Mycobacterium bovis in cattle depleted of WC1 $1+\gamma \delta \mathrm{T}$ cells. Infect Immun. 2002;70(3):1488-500.

38. Guzman E, Hope J, Taylor G, Smith AL, Cubillos-Zapata C, Charleston B. Bovine $\gamma \delta \mathrm{T}$ cells are a major regulatory T cell subset. J Immunol. 2014;193(1):208-22. Discusses the regulatory function of bovine $\gamma \delta$ T cells.

39. Buddle BM, De Lisle GW, Pfeffer A, Aldwell FE. Immunological responses and protection against Mycobacterium bovis in calves vaccinated with a low dose of BCG. Vaccine. 1995;13(12):1123-30.
40. Buddle BM, Parlane NA, Keen DL, Aldwell FE, Pollock JM, Lightbody K, et al. Differentiation between Mycobacterium bovis BCG-vaccinated and M. bovis- infected cattle by using recombinant mycobacterial antigens. Clin Diagn Lab Immunol. 1999;6(1):1-5.

41. Vordermeier HM, Whelan A, Cockle PJ, Farrant L, Palmer N, Hewinson RG. Use of synthetic peptides derived from the antigens ESAT-6 and CFP-10 for differential diagnosis of bovine tuberculosis in cattle. Clin Diagn Lab Immunol. 2001;8(3):571-8.

42. Buddle BM, Wedlock DN, Parlane NA, Corner LA, De Lisle GW, Skinner MA. Revaccination of neonatal calves with Mycobacterium bovis BCG reduces the level of protection against bovine tuberculosis induced by a single vaccination. Infect Immun. 2003;71(11):6411-9.

43. Hope JC, Thom ML, Villarreal-Ramos B, Vordermeier HM, Hewinson RG, Howard CJ. Vaccination of neonatal calves with Mycobacterium bovis BCG induces protection against intranasal challenge with virulent M. bovis. Clin Exp Immunol. 2005;139(1):48-56.

44. Skinner MA, Buddle BM, Wedlock DN, Keen D, De Lisle GW, Tascon RE, et al. A DNA prime-Mycobacterium bovis BCG boost vaccination strategy for cattle induces protection against bovine tuberculosis. Infect Immun. 2003;71(9):4901-7.

45. Wedlock DN, Denis M, Skinner MA, Koach J, De Lisle GW, Vordermeier HM, et al. Vaccination of cattle with a $\mathrm{CpG}$ oligodeoxynucleotide-formulated mycobacterial protein vaccine and Mycobacterium bovis BCG induces levels of protection against bovine tuberculosis superior to those induced by vaccination with BCG alone. Infect Immun. 2005;73(6):3540-6.

46.• Vordermeier HM, Villarreal-Ramos B, Cockle PJ, McAulay M, Rhodes SG, Thacker T, et al. Viral booster vaccines improve Mycobacterium bovis BCG-induced protection against bovine tuberculosis. Infect Immun. 2009;77(8):3364-73. Identifies that BCG prime and virus vector boost enhances protection against TB and that central memory cells may be a correlate of protection.

47. Waters WR, Palmer MV, Nonnecke BJ, Thacker TC, Scherer CFC, Estes DM, et al. Efficacy and immunogenicity of Mycobacterium bovis $\triangle \mathrm{RD} 1$ against aerosol $M$. bovis infection in neonatal calves. Vaccine. 2009;27(8):1201-9.

48.• Whelan AO, Clifford D, Upadhyay B, Breadon EL, McNair J, Hewinson GR, et al. Development of a skin test for bovine tuberculosis for differentiating infected from vaccinated animals. J Clin Microbiol. 2010;48(9):3176-81. Demonstrates that use of specific $M$. bovis antigens in a skin test can differentiate infected from $B C G$ vaccinated cattle which could be used as a primary screening test.

49. Whelan AO, Coad M, Upadhyay BL, Clifford DJ, Hewinson RG, Vordermeier HM. Lack of correlation between BCG-induced tuberculin skin test sensitisation and protective immunity in cattle. Vaccine. 2011;29(33):5453-8.

50. Thom ML, McAulay M, Vordermeier HM, Clifford D, Hewinson RG, Villarreal-Ramos B, et al. Duration of immunity against Mycobacterium bovis following neonatal vaccination with bacillus Calmette-Guérin Danish: significant protection against infection at 12, but not 24, months. Clin Vaccine Immunol. 2012;19(8):1254-60. Discusses waning of immunity following $B C G$ vaccination of cattle.

51. Rizzi C, Bianco MV, Blanco FC, Soria M, Gravisaco MJ, Montenegro V, et al. Vaccination with a BCG strain overexpressing $\mathrm{Ag} 85 \mathrm{~B}$ protects cattle against Mycobacterium bovis challenge. PLoS One. 2012;7(12):e51396. Demonstrates that BCG over-expressing Ag85B enhances protection compared to wild-type BCG.

$52 . \bullet$ Parlane NA, Shu D, Subharat S, Wedlock DN, Rehm BH, de Lisle GW, et al. Revaccination of cattle with Bacille Calmette- Guérin two years after first vaccination when immunity has waned, boosted protection against challenge with Mycobacterium bovis. PLoS One. 2014;9(9):e106519. Demonstrates that revaccination with BCG when immunity has waned boost protection against TB in cattle. 
53. Skinner MA, Wedlock DN, Buddle BM. Vaccination of animals against Mycobacterium bovis. Rev Sci Tech Off Int Epiz. 2001;20(1):112-32.

54. Colditz GA, Berkey CS, Mosteller F, Brewer TF, Wilson ME, Burdick E, et al. The efficacy of bacillus Calmette-Guerin vaccination of newborns and infants in the prevention of tuberculosis: metaanalyses of the published literature. Pediatrics. 1995;96(1):29-35.

55. Palmer MV, Waters WR, Whipple DL. Aerosol delivery of virulent Mycobacterium bovis to cattle. Tuberculosis. 2002;82(6):275-82.

56. Buddle BM, Aldwell FE, De Lisle GW, Vordermeier HM, Hewinson RG, Wedlock DN. Low oral BCG doses fail to protect cattle against an experimental challenge with Mycobacterium bovis. Tuberculosis. 2011;91(5):400-5.

57. Wedlock DN, Denis M, Vordermeier HM, Hewinson RG, Buddle BM. Vaccination of cattle with Danish and Pasteur strains of Mycobacterium bovis BCG induce different levels of IFN $\gamma$ postvaccination, but induce similar levels of protection against bovine tuberculosis. Vet Immunol Immunopathol. 2007;118(1-2):50-8.

58. Hope JC, Thom ML, McAulay M, Mead E, Vordermeier HM, Clifford $\mathrm{D}$, et al. Identification of surrogates and correlates of protection in protective immunity against Mycobacterium bovis infection induced in neonatal calves by vaccination with $\mathrm{M}$. bovis BCG pasteur and $\mathrm{M}$. bovis BCG Danish. Clin Vaccine Immunol. 2011;18(3):373-9.

59. Buddle BM, Wards BJ, Aldwell FE, Collins DM, de Lisle GW. Influence of sensitisation to environmental mycobacteria on subsequent vaccination against bovine tuberculosis. Vaccine. 2002;20(78):1126-33.

60. Hope JC, Thom ML, Villarreal-Ramos B, Vordermeier HM, Hewinson RG, Howard CJ. Exposure to Mycobacterium avium induces low-level protection from Mycobacterium bovis infection but compromises diagnosis of disease in cattle. Clin Exp Immunol. 2005;141(3):432-9.

61. Lopez-Valencia G, Renteria-Evangelista T, Williams JJ, LiceaNavarro A, Mora-Valle AD, Medina-Basulto G. Field evaluation of the protective efficacy of Mycobacterium bovis BCG vaccine against bovine tuberculosis. Res Vet Sci. 2010;88(1):44-9.

62. Ameni G, Vordermeier M, Aseffa A, Young DB, Hewinson RG. Field evaluation of the efficacy of Mycobacterium bovis Bacillus Calmette-Guérin against bovine tuberculosis in neonatal calves in Ethiopia. Clin Vaccine Immunol. 2010;17(10):1533-8. Demonstrates protection against TB in cattle in a natural transmission study.

63. Khatri B, Whelan A, Clifford D, Petrera A, Sander P, Vordermeier HM. BCG $\Delta z m p 1$ vaccine induces enhanced antigen specific immune responses in cattle. Vaccine. 2014;32(7):779-84.

64. Waters WR, Palmer MV, Nonnecke BJ, Thacker TC, Scherer CFC, Estes DM, et al. Failure of a Mycobacterium tuberculosis $\triangle \mathrm{RD} 1$ $\Delta$ panCD double deletion mutant in a neonatal calf aerosol $M$. bovis challenge model: comparisons to responses elicited by $M$. bovis bacille Calmette-Guérin. Vaccine. 2007;25(45):7832-40.

65. Khare S, Hondalus MK, Nunes J, Bloom BR, Garry Adams L. Mycobacterium bovis $\Delta \mathrm{leuD}$ auxotroph-induced protective immunity against tissue colonization, burden and distribution in cattle intranasally challenged with Mycobacterium bovis Ravenel S. Vaccine. 2007;25(10):1743-55.

66. Blanco FC, Bianco MV, Garbaccio S, Meikle V, Gravisaco MJ, Montenegro V, et al. Mycobacterium bovis $\Delta$ mce2 double deletion mutant protects cattle against challenge with virulent $M$. bovis. Tuberculosis. 2013;93(3):363-72.

67. Maue AC, Waters WR, Palmer MV, Whipple DL, Minion FC, Brown WC, et al. CD80 and CD86, but not CD154, augment DNA vaccine-induced protection in experimental bovine tuberculosis. Vaccine. 2004;23(6):769-79.

68. Cai H, Tian X, Hu XD, Li SX, Yu DH, Zhu YX. Combined DNA vaccines formulated either in DDA or in saline protect cattle from Mycobacterium bovis infection. Vaccine. 2005;23(30):3887-95.

69. Skinner MA, Wedlock DN, De Lisle GW, Cooke MM, Tascon RE, Ferraz JC, et al. The order of prime-boost vaccination of neonatal calves with Mycobacterium bovis BCG and a DNA vaccine encoding mycobacterial proteins Hsp65, Hsp70, and Apa is not critical for enhancing protection against bovine tuberculosis. Infect Immun. 2005;73(7):4441-4.

70. Maue AC, Waters WR, Palmer MV, Nonnecke BJ, Minion FC, Brown WC, et al. An ESAT-6:CFP10 DNA vaccine administered in conjunction with Mycobacterium bovis BCG confers protection to cattle challenged with virulent $M$. bovis. Vaccine. 2007;25(24):4735-46.

71. Wedlock DN, Denis M, Painter GF, Ainge GD, Vordermeier HM, Hewinson RG, et al. Enhanced protection against bovine tuberculosis after coadministration of Mycobacterium bovis BCG with a mycobacterial protein vaccine-adjuvant combination but not after coadministration of adjuvant alone. Clin Vaccine Immunol. 2008;15(5):765-72.

72. Dean G, Whelan A, Clifford D, Salguero FJ, Xing Z, Gilbert S, et al. Comparison of the immunogenicity and protection against bovine tuberculosis following immunization by BCG-priming and boosting with adenovirus or protein based vaccines. Vaccine. 2014;32(11):1304-10.

73. Jones GJ, Steinbach S, Clifford D, Baldwin SL, Ireton GC, Coler RN, et al. Immunisation with ID83 fusion protein induces antigen-specific cell mediated and humoral immune responses in cattle. Vaccine. 2013;31:5250-5.

74. Dean G, Clifford D, Gilbert S, McShane H, Hewinson RG, Vordermeier HM, et al. Effect of dose and route of immunisation on the immune response induced in cattle by heterologous Bacille Calmette-Guérin priming and recombinant adenoviral vector boosting. Vet Immunol Immunopathol. 2014;158(3-4):208-13.

75. Schiller I, Oesch B, Vordermeier HM, Palmer MV, Harris BN, Orloski KA, et al. Bovine tuberculosis: a review of current and emerging diagnostic techniques in view of their relevance for disease control and eradication. Transbound Emerg Dis. 2010;57(4):205-20.

76. Vordermeier HM, Chambers MA, Cockle PJ, Whelan AO, Simmons J, Hewinson RG. Correlation of ESAT-6-specific gamma interferon production with pathology in cattle following Mycobacterium bovis BCG vaccination against experimental bovine tuberculosis. Infect Immun. 2002;70(6):3026-32.

77. Whelan AO, Wright DC, Chambers MA, Singh M, Hewinson RG, Vordermeier HM. Evidence for enhanced central memory priming by live Mycobacterium bovis BCG vaccine in comparison with killed BCG formulations. Vaccine. 2008;26(2):166-73.

78. Whelan AO, Villarreal-Ramos B, Vordermeier HM, Hogarth PJ. Development of an antibody to bovine IL-2 reveals multifunctional CD4 T EM cells in cattle naturally infected with bovine tuberculosis. PLoS One. 2011;6(12):e29194.

79. Rhodes SG, McKinna LC, Steinbach S, Dean GS, Villarreal-Ramos B, Whelan AO, et al. Use of antigen-specific interleukin-2 to differentiate between cattle vaccinated with Mycobacterium bovis BCG and cattle infected with M. bovis. Clin Vaccine Immunol. 2014;21(1):39-45.

80. Vordermeier M, Gordon SV, Hewinson RG. Mycobacterium bovis antigens for the differential diagnosis of vaccinated and infected cattle. Vet Microbiol. 2011;151(1-2):8-13.

81. Sidders B, Pirson C, Hogarth PJ, Hewinson RG, Stoker NG, Vordermeier HM, et al. Screening of highly expressed mycobacterial genes identifies Rv3615c as a useful differential diagnostic antigen for the Mycobacterium tuberculosis complex. Infect Immun. 2008;76(9):3932-9.

82. Chambers MA, Carter SP, Wilson GJ, Jones G, Brown E, Hewinson $\mathrm{RG}$, et al. Vaccination against tuberculosis in badgers and cattle: an overview of the challenges, developments and current research priorities in Great Britain. Vet Rec. 2014;175(4):90-6.

83. Jones GJ, Whelan A, Clifford D, Coad M, Vordermeier HM Improved skin test for differential diagnosis of bovine tuberculosis by the addition of Rv3020c-derived peptides. Clin Vaccine Immunol. 2012;19(4):620-2.

84. Chen S, Parlane NA, Lee J, Wedlock DN, Buddle BM, Rehm BHA. New skin test for detection of bovine tuberculosis on the basis of antigen-displaying polyester inclusions produced by recombinant Escherichia coli. Appl Environ Microbiol. 2014;80(8):2526-35. 